\title{
A Stochastic Hydraulic Modelling Approach to Determining the Probable Maximum Staging of Ice-Jam Floods
}

\author{
K. E. Lindenschmidt ${ }^{*}$ and P. Rokaya \\ Global Institute for Water Security, University of Saskatchewan, 11 Innovation Blvd., Saskatoon, Saskatchewan S7N 3H5, Canada
}

Received 15 May 2018; revised 09 Oct 2018; accepted 21 Oct 2018; published online 29 Jun 2019

\begin{abstract}
There is a need to determine the maximum backwater staging possible from ice jam flooding along high flood risk prone sections of northern rivers. Similar to the probable maximum flood $P M F$, which is primarily estimated for the most extreme open-water floods, probable maximum floods from ice jamming $P M F_{\text {ice }}$ can provide upper thresholds of water level elevations so essential for infrastructure designed in and along cold-region rivers. However, the processes for maximum ice-jam flooding are quite different from those of extreme open-water floods which requires river ice processes to be incorporated into the calculation approach. This paper presents a novel method for estimating the probable maximum staging from ice-jam floods. The method is based on the implementation of a deterministic hydraulic model that mimics ice jam processes and is nested in a stochastic framework to carry out Monte-Carlo simulations to randomise parameter and boundary condition value inputs for many hundreds of simulations. This stochastic approach provides the frequency distributions of many of the boundary conditions used to force the river ice hydraulic model. The stochastic modelling framework yields ensembles of backwater levels from which the maximum level provides an indication of the probable maximum staging possible, the $P M F_{i c e}$.
\end{abstract}

Keywords: Athabasca River, ice-jam flooding, probable maximum backwater staging, RIVICE, stage frequency distribution, stochastic modelling.

\section{Introduction}

\subsection{Stochasticity Modelling of River Ice Processes}

River ice processes and flooding induced by ice jamming during the ice cover breakup period in spring along many northern rivers is dictated by stochastic processes (White, 1999), more so than open water flood events. This is illustrated using the flow $v s$. water level graph in Figure 1. Whereas open water discharge and water levels can be associated with a smooth deterministic curve, backwater levels from ice accumulations or the more severe ice jam events cannot. For this particular gauge record between 1963 and 2010, the highest open-water staging on record is $241.841 \mathrm{~m}$ a.s.l. for a discharge of 4,700 $\mathrm{m}^{3} / \mathrm{s}$. Interestingly, ice jamming flood events can cause much higher staging at less than half of the maximum recorded openwater flood discharge. The maximum staging for the ice jam of 1997 attained a water level of $247 \mathrm{~m}$ a.s.l. for a discharge of $2,290 \mathrm{~m}^{3} / \mathrm{s}$. In addition, staging from ice jam flood events can be similar with substantial variations in the discharge. For example, the three ice jam floods of 1977, 1989 and 1996 all attain-

\footnotetext{
* Corresponding author. Tel.: +1 (306) 9666174; fax: +1 (306) 9661193. E-mail address: karl-erich.lindenschmidt@usask.ca(K. E. Lindenschmidt).
}

ISSN: $1726-2135$ print/1684-8799 online

C) 2019 ISEIS All rights reserved. doi:10.3808/jei.201900416 ed similar observed flood water levels, however the discharges for the 1989 and 1977 events were approximately $1 / 4$ and $1 / 2$, respectively, of that of the 1996 event. Instead of a smooth fit, ice jam events fall within an envelope, also shown in Figure 1.

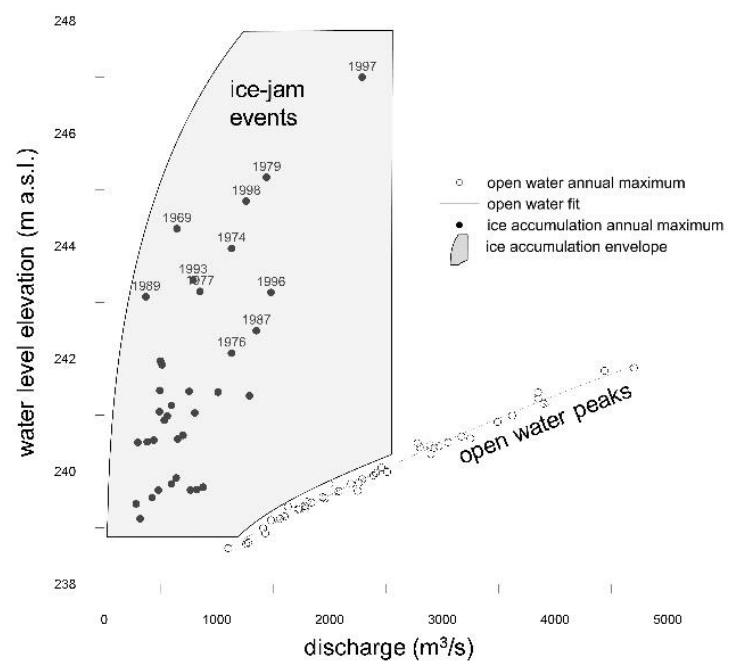

Figure 1. Flow vs. water levels for annual open water and ice accumulated maximum water level elevations at the gauge "Athabasca River below Fort McMurray" for the years 1963 2010. Theoretical shape of envelope is adapted from Tuthill et al. (1996). 
Since they are chaotic in nature, ice jamming events, as with the open-water floods, can be fit with extreme value stage frequency distributions, as shown in Figure 2 for the same data provided in Figure 1. The reason for the stochasticity in the discharge/water level relationship is that similar backwater level profiles can occur through different water and ice flow conditions leading to ice jamming including: (i) inflowing discharge, (ii) volume of ice rubble forming the ice accumulation, (iii) location of the ice jam toe and (iv) initial water and ice cover levels prior to the jam. These are just a few examples of the differences that can occur which may lead to similar backwater staging. Lindenschmidt et al. (2016) shows different ice jam configuration that can lead to the same $\mathrm{T}=100$-year flood levels at a gauge along a river reach with reoccurring ice jam events.

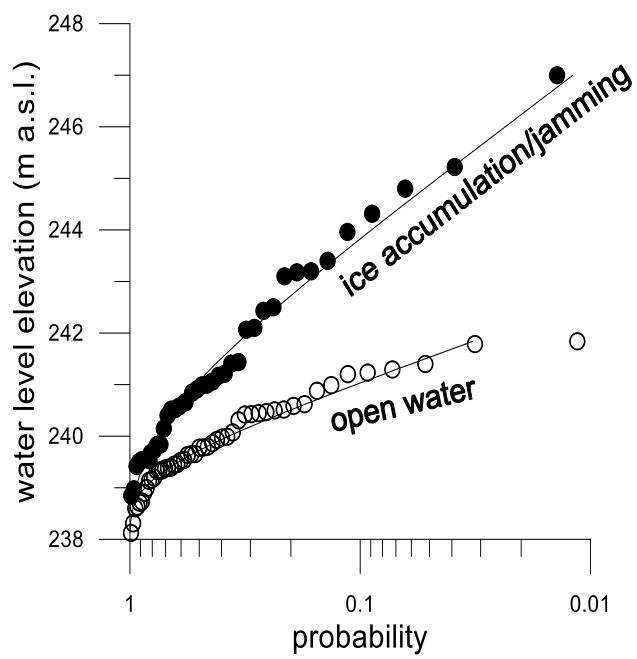

Figure 2. Stage frequency distributions established from the data in Figure 1 for annual open water and ice accumulation/ jamming maximum water levels.

\subsection{Stochastic Modelling of River Ice Processes}

River ice models are useful tools to simulate ice jams and subsequent flooding along rivers. For certain ice jam events, when the boundary conditions are known, the parameters of the model, which describe, for example certain characteristics of the ice and transport mechanisms, can be calibrated to obtain agreement between simulated and observed variables such as backwater levels and ice jam extent. However, some of these boundary conditions are difficult to predict, particularly the volume of inflowing ice rubble and the location of the ice jam toe. Some attempts have been made to determine the volume of inflowing ice rubble equalling the:

$=$ length of the ice cover extending upstream of the ice jam location, determined from ground observations and remote sensing (Zhang et al., 2017);

$\times \quad$ ice thicknesses measured through ground surveys or remote sensing technique or simulated using a heat budget model (Hosseini et al., 2017);

$\times \quad$ width of the river.
However, the amount of ice ablation during the breakup period is difficult to quantify leading to only an estimate of the ice volumes available for jamming. The toe location can change, as well, from event to event due to many factors influencing the arrest of ice floes at a lodgement to form the jam, such as different ice thicknesses along the ice cover prior to jamming and geomorphological features such as the presence of islands and sand bars.

One approach to capture the stochasticity is to embed a deterministic river ice model into a Monte-Carlo Analysis (MOCA) framework. The model simulations are repeated many times within the framework with each simulation having a different set of parameters and boundary condition values. These many simulations yield ensembles of the output variables, such as backwater levels. Values can be extracted from each ensemble at a particular river chainage, ideally at a gauge location, to construct a frequency distribution from simulated values. Comparison of this simulated frequency distribution with distributions formed from observed values, such as in Figure 2, provides an opportunity to calibrate the stochastic modelling framework and determine the distribution of boundary condition values that are otherwise difficult or even impossible to determine. Some frequency distributions can be determined from available gauge data, such as inflowing discharges during ice cover breakup or ice jam events. However, other frequency distributions, such as inflowing rubble ice volume would need to be adjusted until the frequency distributions of the simulated backwater levels coincided with the stage frequency distribution established from observed water levels during past ice jam events.

The first objective of this paper is to introduce a novel methodology of calibrating a boundary condition frequency distribution with a stochastic modelling framework. Calibrating the frequency distributions of the volume of ice forming ice jams has been reported in Lindenschmidt et al. (2016); however, incorporating the calibration of the initial water levels during the breakup period in the overall stochastic modelling framework calibration is a novel extension to the methodology. It is hoped that such a stochastic modelling approach could be applied to other fields of hydrology where a strong stochastic component in the process description is present, such as precipitation and antecedent soil moisture conditions in hydrological modelling. The second objective is described in the next subsection.

\subsection{Probable Maximum Ice-Jam Flood}

The probable maximum flood $(P M F)$ is defined by the World Meteorological Organization as "the theoretical maximum flood that poses extremely serious threats to the flood control of a given project in a design watershed" (WMO, 2009). An important input to the $P M F$ is the probable maximum precipitation $(P M P)$ also defined by the WMO as "the greatest depth of precipitation for a given duration meteorologically possible for a design watershed or a given storm area at a particular location at a particular time of year, with no allowance made for long-term climatic trends" (WMO, 2009). The 
$P M F$ is a useful value used to design critical infrastructure, such as dams, spillways, dikes and other hydraulic structures, whose failure could lead to extensive loss of life, damages and negative impacts to society. Improvements have been made in $P M F$ estimations using modelling systems that couple hydrological with hydraulic models, which can translate the largest possible precipitation fields into overland runoff. The runoff is then routed to determine the highest discharges and corresponding water levels that may occur along a river (e.g., Lindenschmidt et al., 2008; Felder et al., 2017). Not only are the characteristics of the meteorological forcing functions to the modelling systems considered (e.g., $P M F$ ), but also critical hydrological conditions that cater to maximum runoff events are incorporated (e.g., high soil saturation). Some adjustment to the $P M F$ value can be made by including the probability of dike breaches (Vorogushyn et al., 2012), which diverts flood-water from the river channel into the hinterlands.

Extremely high discharges of water and ice floes can lead to extreme ice-jam events with subsequent backwater staging and flooding. However, discharges excessively extreme will produce forces on the ice jam too great for the jam to remain stable leading to the collapse of the jam and a release of retained ice and water to form a surge and potentially another jam further downstream. This threshold across which an incrementtal increase in the discharge of water and/or ice which can transition an ice jam from being a stable ice jam producing the most extreme backwater staging to the collapse of the ice jam is coined here as the probable maximum ice jam flood $P M F_{\text {ice. }}$ It can be determined by extending the number of simulations of the stochastic modelling framework, as described above for the first objective, many hundreds or thousands of times until the backwater staging values approach an asymptote to a potentially maximum water level elevation. This is a novel concept in ice-jam flood modelling and its presentation here fulfils the second objective of this paper.

\section{Study Site}

The two objectives of this paper were reached by modelling the ice hydraulics of the Athabasca River at Fort McMurray in Alberta, Canada, shown in Figure 3. This section of the Athabasca River is very prone to ice jamming since (i) there is a sharp decrease in river slope from the stretch upstream of the bridges to the downstream reach, (ii) the lower sloping reach is wider and has larger cross-sectional areas causing the flow from the upstream reach to slow down substantially for ice to accumulate and form jams; the bridge piers act as barriers to potentially slow down ice floe movement, (iii) the low sloping section is riddled with islands and sandbars that form barriers to ice flow or are potential sites where ice can ground, (iv) the Clearwater River tributary can be an additional source of ice and water to promote and exacerbate ice jamming downstream of the confluence, and (v) the steeper reach upstream of the bridges is dotted with rapids at which extra ice can be generated to form thick consolidated ice covers along the reach; the additional ice can increase the ice volume of jams formed downstream in the Fort McMurray area.

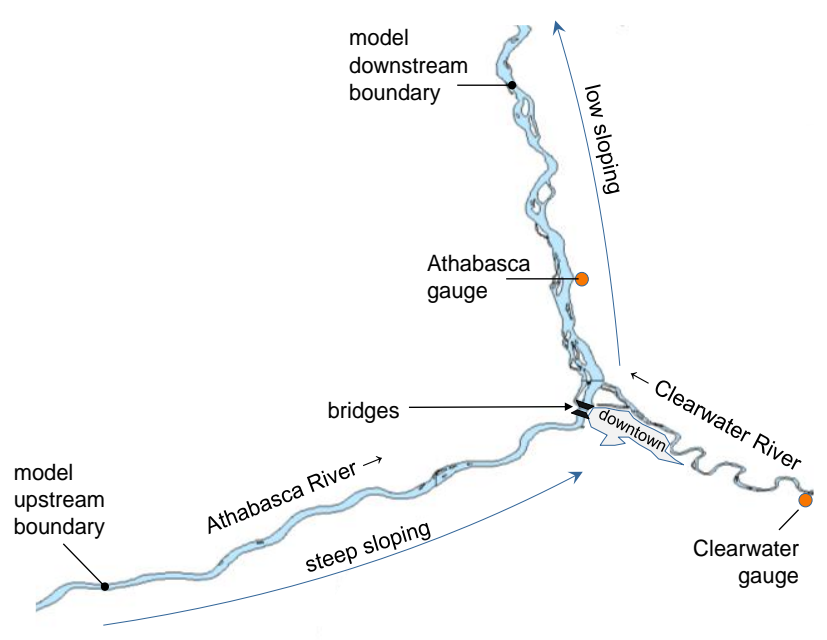

Figure 3. Athabasca River at Fort McMurray.

\section{Methodology}

\subsection{RIVICE Model}

RIVICE is a hydraulic river ice model that mimics important ice processes both during river freeze-up and ice-cover breakup (ECCC, 2013; Lindenschmidt, 2017a). RIVICE is a one-dimensional model (variations in the longitudinal direction), hydrodynamic model that dynamically simulates the progression of ice-cover and ice-jam formation and collapse. Hence, not only equilibrium jams but under-developed jams (during the early phase of jam formation leading to an equilibrium jam) and over-shot jams (temporarily formed by a surge of inflowing ice before collapsing to the morphology of an equilibrium jam or smaller or completely flushing out the ice from the jam location). The progression, shoving and collapse of an ice cover or ice jam is determined by tracking the balance of forces applied to the jam ice cover, which include (refer to Figures 4 and 5):

- Thrust $F_{T}$, a force induced on the ice jam front due to the impact of the water's flow velocity against the icejam front of thickness $F T$,

- Drag $F_{D}$ applied by the flowing water along the underside of the ice cover,

- Weight $F_{w}$ of the ice jam in the river slope direction.

These forces are countered by:

- Friction $F_{F}$ between the ice jam cover and the river banks parameterised by K1TAN, the ratio of longitudinal stresses along the ice cover shed laterally towards the banks,

- Cohesion $F C$ at the ice-cover/river bank interface, a more prevalent feature during freeze-up jamming when the ice cover is more likely to freeze and adhere to the river banks,

- Internal resistance $F_{I}$ parameterized by $K 2$ which is the proportion of longitudinal stresses along the jam being transferred vertically along the jam's thickness $h$. 

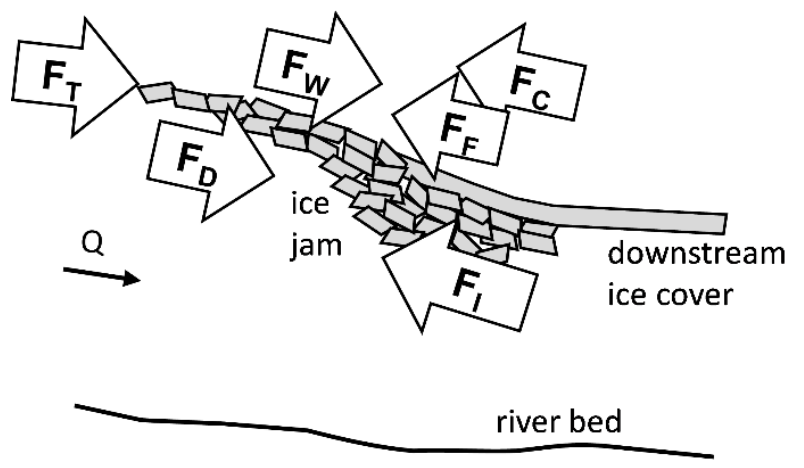

Figure 4. Forces applied to an ice jam.

Porosity of the ice cover $P C$ influences the extent of the jam upstream from the inflowing ice volume in the form of ice blocks or frazil pans with an average thickness $S T$ and porosity $P S$. Additional ice transport parameters include the amount of ice eroded from the ice cover's underside, should the average flow velocity exceed a threshold $v_{e r}$, which can be deposited further downstream along the ice-cover when a cross-section is reached in which the flow velocity drops below another threshold $v_{\text {dep }}$. Flow is also influenced by the hydraulic roughness of the river bed $n_{\text {bed }}=f($ constant $)$ and the ice cover $n_{\text {ice }}=f($ ice thickness).

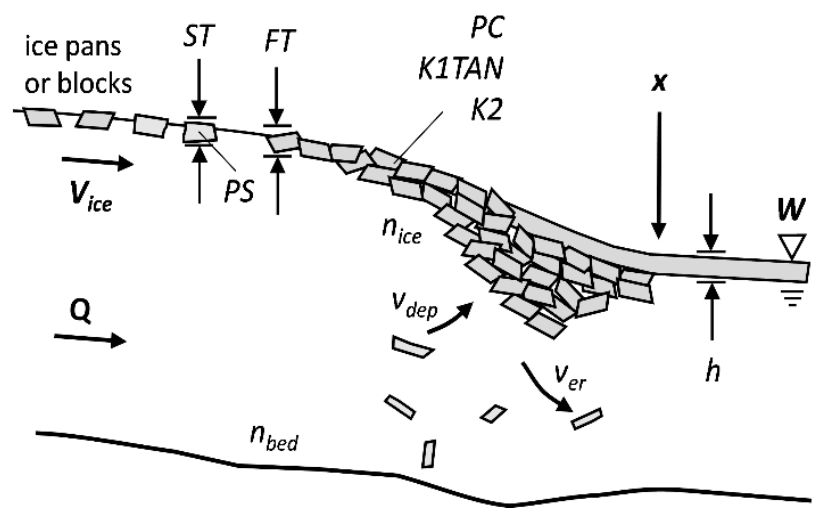

Figure 5. Parameters (normal font) and boundary conditions (bold font) used to mimic ice processes in RIVICE.

Important boundary conditions are the upstream discharge of water flowing into the model domain Q, the downstream water level elevation $W$, the location of the ice-jam toe $x$ and the upstream volume of ice $V_{\text {ice }}$ flowing into the model domain. $V_{\text {ice }}$ can be inserted explicitly as a volume of ice per time step, which is usually the case for ice floes broken up from upstream ice covers during breakup, or be formed by frazil ice along the open-water portion upstream of the ice-jam front when the water temperature drops to $0{ }^{\circ} \mathrm{C}$ and the air temperature is freezing.

\subsection{Monte-Carlo Framework}

RIVICE was embedded in a Monte-Carlo Analysis (MO-
CA) framework to carry out the stochastic modelling. Conceptualizations of the framework are provided in Figures 6 and 7. A general description of the MOCA framework is given in this paragraph. The following two paragraphs provide more detail of the distinctions between the two figures, respectively, stochastic modelling for (i) end of breakup to calibrate the frequency distribution of the downstream water level boundary condition and (ii) instantaneous maxima to determine the frequency distribution of the inflowing rubble ice volume. The framework allows the model simulations to be repeated many 100 s of times with each simulation having a different set of parameter and boundary condition values. The values are randomly selected from probability distributions. Where information on the distribution type is unknown or unavailable, a uniform distribution is used with the values varying within a range of values that were compiled from other river ice modelling studies. Uniform distributions were generally applied to parameter values. Boundary condition values were derived from gauge recordings and the upstream flow boundary condition data generally follows an extreme value distribution. The Gumbel distribution was used since it requires fitting only two factors, location and scale, instead of three, which is the case for many other distributions. The Gumbel distribution also lends itself well to shorter time series which, in our case, were no longer than 37 years. The location of the ice jam toe follows a uniform distribution since information on the toe location are sparse.

\subsection{Calibrating the Downstream Water Level Distribution at the End of Breakup}

Figure 6 accompanies the following methodological description. The first MOCA fitting was carried out for the end of the ice cover breakup periods. The flow recorded on the last Bflag ("B"s often accompany flow data recorded in Canada to indicate the presence or influence of an ice cover on the staging recorded at a gauge) were compiled, to which a Gumbel distribution was fit, and was used as the upstream boundary condition. A Gumbel distribution was also fit to the water level elevations recorded on the date of the beginning of freeze-up, the first B-flag. However, the gauge is not located at the downstream boundary and the frequency distribution was shifted down an amount corresponding to the drop in elevation along the river slope proportional to the distance between the gauge and the downstream boundary location. However, this can only be an initial estimate of the distribution since the water level and the ice cover are somewhat elevated from the freeze-up levels during breakup (Lindenschmidt et al., 2012). Ice covers usually break off from the river banks as they are lifting up during the higher discharges from increased runoff throughout the breakup period. The volume of ice is assumed to be zero, since after the date of the last B-flag, the ice cover front will have passed the gauge in the downstream direction and backwater effects from downstream ice accumulations will be negligible. This provides an opportunity to calibrate the distribution of the downstream water level boundary. The model is run 37 times using a randomised set of parameters and boundary condition values drawn from their corresponding distributions to yield an ensemble of water level profiles. The stages at the 
gauge location are extracted from the ensemble to become the plotting positions for the fitted "simulated" stage frequency distributions, which is compared to the "observed" stage frequency distribution of the stages recorded on the date immediately after the last B-flags.
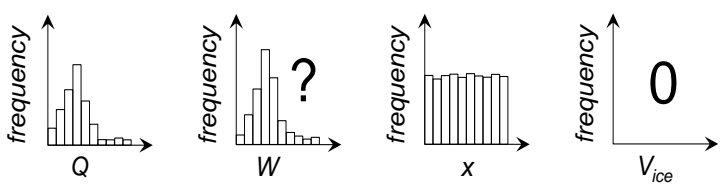

Monte-Carlo simulations

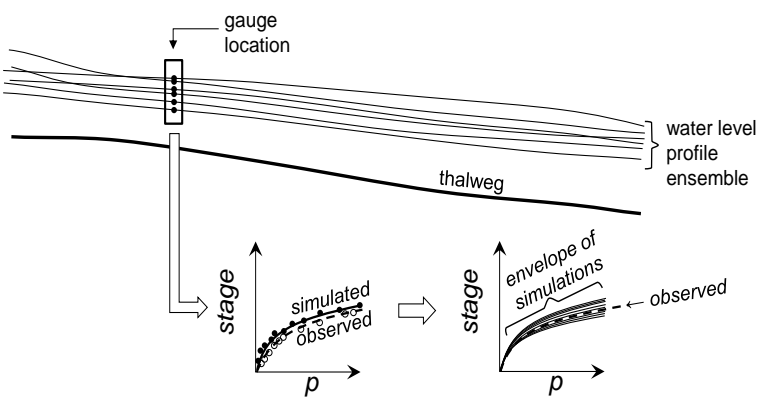

Figure 6. Conceptualisation of the Monte-Carlo Analysis modelling framework to calibrate the frequency distribution of the downstream water level boundary condition $W_{d / s}$.

The above process is repeated several times to yield an ensemble of simulated stage frequency distributions. If the observed stage frequency does not reasonably fit within the simulated envelope of stage frequency distributions, the parameters, location and scale, of the input water level frequency distribution is adjusted and the process is repeated. The downstream water level distribution is deemed calibrated when the observed stage frequency distribution coincides approximately along the centre of the simulated stage frequency distribution envelope.

\subsection{Calibrating the Inflowing Volume of Ice Forming Ice Jams}

The next distribution to be calibrated is the volume of inflowing rubble ice that forms ice jams. Figure 7 provides a depiction of the following description of the Monte-Carlo approach. Here, a Gumbel distribution is also assumed, which is supported by other studies (Lindenschmidt et al., 2016; Aaltonen and Huokuna, 2017). The distribution compiled from the instantaneous maximum flows occurring during ice jam events (37 events) served as the upstream boundary in the Monte Carlo framework. The previously calibrated water level distribution remains as the downstream boundary. An initial distribution is assumed for the volume of inflowing ice. A set of 37 simulations are then carried out with parameters and boundary condition values randomly chosen from their corresponding distributions yielding an ensemble of 37 water level profiles. The 37 water level values at the chainage of the gauge serve as the plotting positions for the extreme value fitting. Again, the process is repeated to yield an ensemble of simulated stage frequency distributions. If there is a bias between the observed and the median of the envelope of simulated stage frequency distributions, the parameters of the input ice volume distribution is adjusted and the analysis is repeated. The ice volume distribution is considered calibrated when the observed stage frequency distribution coincides reasonably well with the centre of the envelope of simulated stage frequency distributions.
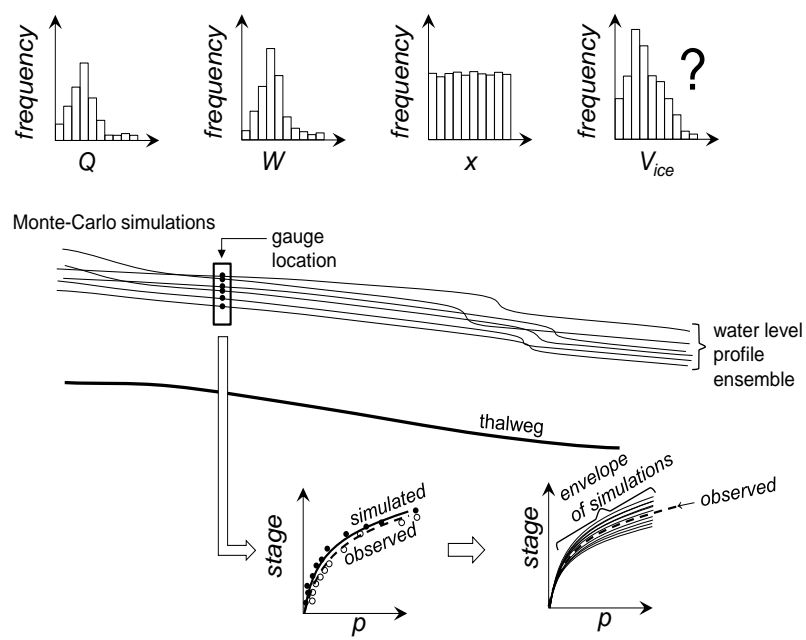

Figure 7. Conceptualisation of the Monte-Carlo Analysis modelling framework to calibrate the frequency distribution of inflowing volume of ice rubble $V_{\text {ice }}$.

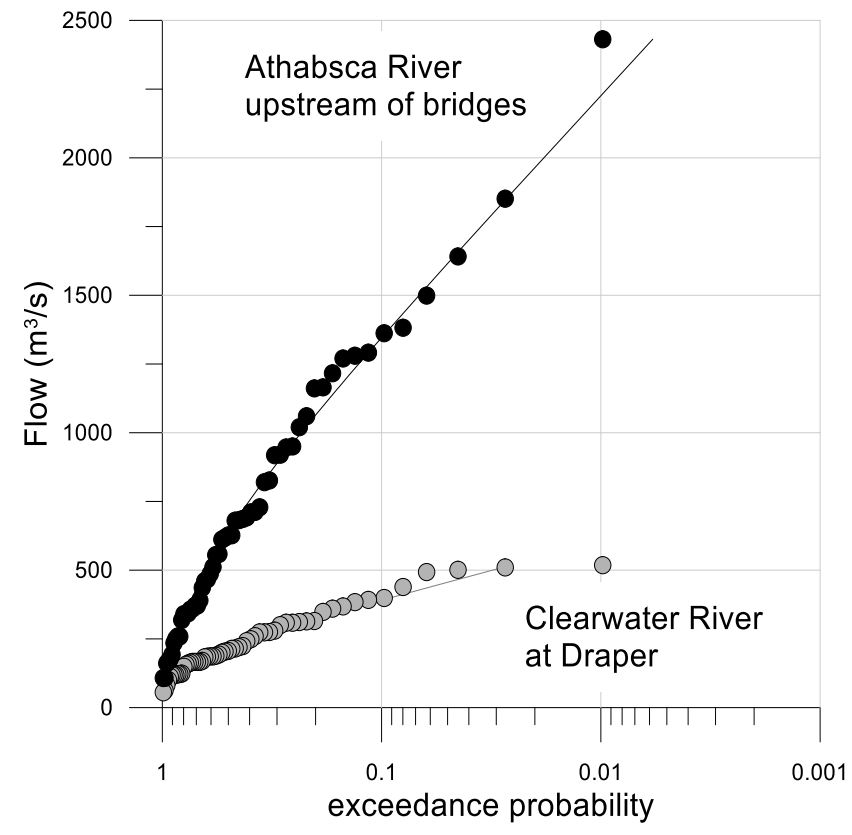

Figure 8. Frequency distributions of the end-of-breakup flows along the Athabasca and Clearwater rivers upstream of the two river's confluence. 


\section{Model Data and Setup}

\subsection{Bathymetry}

Cross-sections were available approximately every $1 \mathrm{~km}$ along the Athabasca River with a higher density of cross-sections in the immediate vicinity of Fort McMurray. The crosssections provided the morphological input to the river hydraulic model.

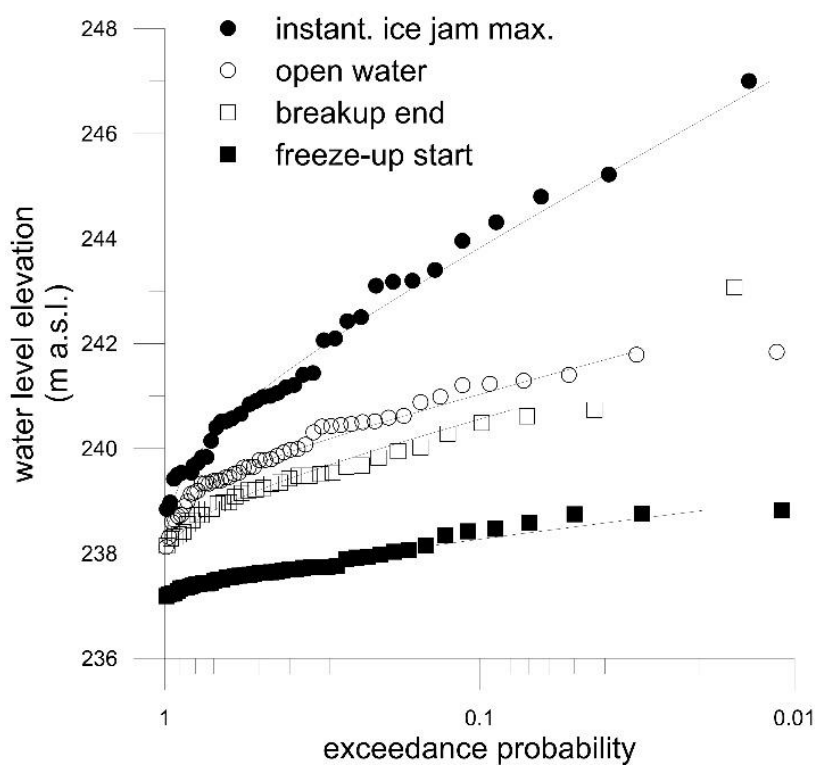

Figure 9. Stage frequency distributions of maxima for icejam, open water, end-of-breakup and start-of-freeze-up events.

\subsection{Gauge Data}

Water levels and flows are recorded at two gauges: Athabasca River below Fort McMurray (\#07DA001), hereafter referred to as the Athabasca gauge, and Clearwater River at Draper (\#07CD001), hereafter indicated as the Clearwater gauge. The flow along the Athabasca River upstream of the bridges was calculated as the difference between the two-gauge recordings. Flow frequency distributions of each at breakup are provided in Figure 8 . There is only a weak correlation between all the flows recorded at each gauge at the end of breakup $\left(r^{2}=\right.$ 0.35 ) and no correlation for flows larger than approximately $1: 10$ year AEP $\left(r^{2}=0.01\right)$. Hence, it is reasonable to assume that the two distributions are independent of each other.

Stage frequency distributions of the water level elevations recorded at the Athabasca gauge are shown in Figure 9. Instantaneous maxima of the water level elevations were made available for each ice-jam event by Water Survey of Canada. Daily mean values suffice for the frequency distributions of the water-level elevations at the end of breakup and beginning of freeze-up. The open water frequency distribution, constructed from the maximum day mean water level elevation value during each open-water season, is provided as a reference, again showing the greater extremity of ice-induced flooding over open-water floods.
The model was previously calibrated for a number of severe ice-jam flood events, particularly 1977, 1978, 1979 and 1997 and the reader is referred to Lindenschmidt (2017a, $2017 \mathrm{~b}$ ) for the calibration and validation of the model.

\section{Results and Discussions}

\subsection{Calibration of Frequency Distributions}

Figure 10 (top panel) shows an ensemble of longitudinal water level profiles from the Monte-Carlo analysis as conceptualized in Figure 6, in which the volume of ice remained zero but an ice cover downstream of the gauge was still possible. The initial water level elevation distribution of the downstream boundary condition was assumed to follow the same pattern as the freeze-up stage frequency distribution, only shifted downward in elevation proportional to the river bed slope and the distance downstream of the boundary condition from the gauge. The frequency distribution of this downstream boundary condition was then gradually shifted upward in elevation until the simulated stage frequency distributions fit reasonably well to the observed stage frequency distribution established from the water levels recorded at the gauge during end-of-breakup periods. The figure indicates the location of the gauge from which the water level elevations were extracted to serve as plotting positions to fit the simulated extreme value functions, as shown in Figure 11. In a similar fashion the volume of inflowing ice distribution was calibrated until the simulated and observed instantaneous maximum stage frequency distributions coincided (Figure 11, right panel).

(a) Water level profile ensembles for end-of-breakup scenarios
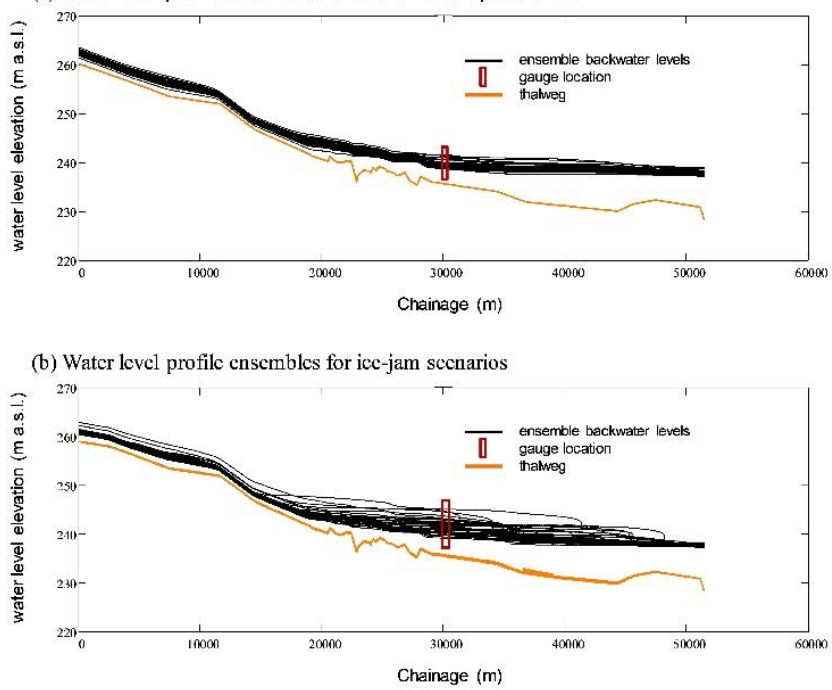

Figure 10. Ensemble of water level profiles for (a) end-ofbreakup and (b) ice jam scenarios.

The Monte-Carlo analyses were repeated to produce several sets of water level profiles to produce ensembles of simulated stage frequency distributions for both the end-of-breakup and ice jam events, produced in Figure 12. The observed stage 
frequency distributions lie within the envelope of simulated stage frequency distribution ensembles, verifying the distributions calibrated for the downstream water level boundary condition and volume of inflowing ice.
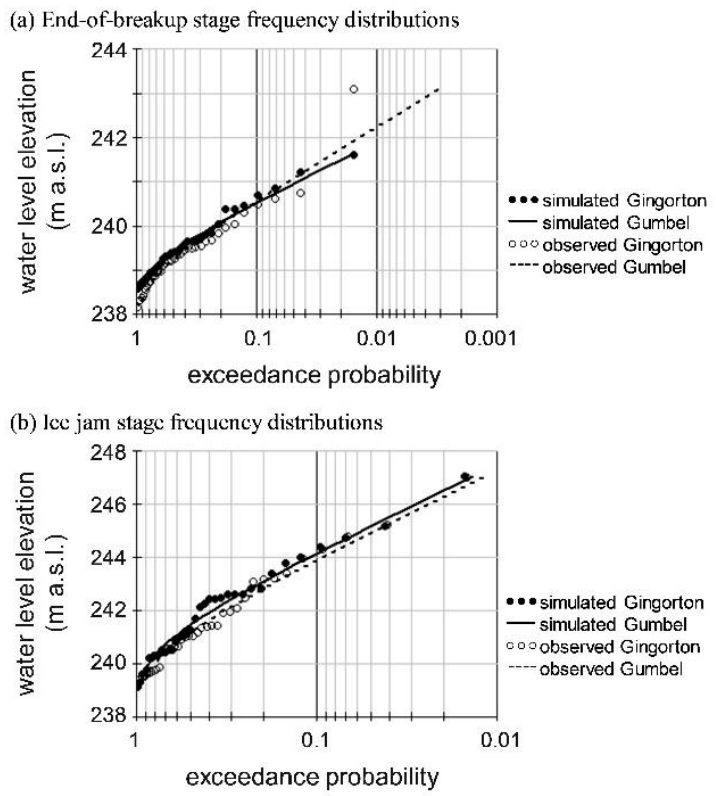

Figure 11. Simulated and observed stage frequency distributions for (a) end-of-breakup and (b) ice jam scenarios. The line and circles denote Gumbel and Gringorton distributions, respectively.

(a) End-of-breakup stage frequency distributions

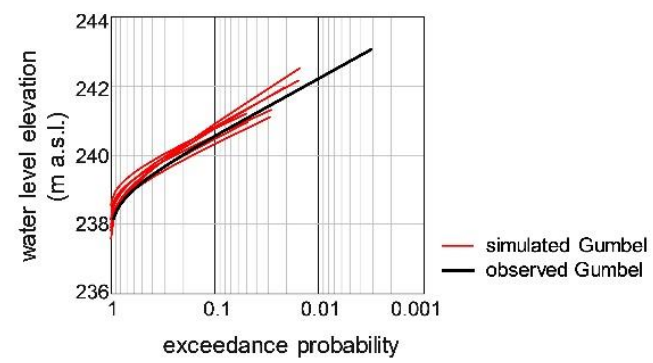

(b) Ice jam stage frequency distributions

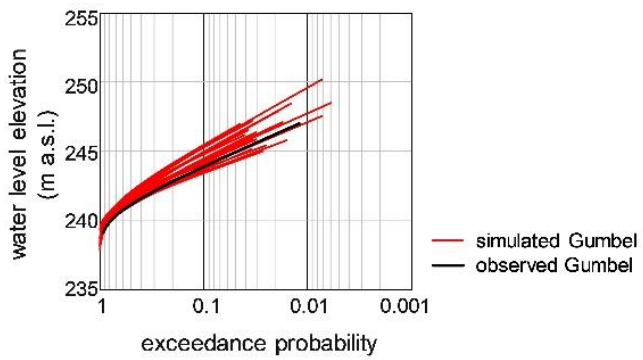

Figure 12. Observed and ensembles of simulated stage frequency distributions for (a) end-of-breakup and (b) ice jam scenarios.
The histogram of the volume of inflowing ice frequency distribution is shown in Figure 13. The extreme value function parameters, location and scale, equal 6.2 and 2.7 million $\mathrm{m}^{3}$, respectively. The frequency distributions of the volume of ice can also be substantiated by comparing to another study in which the volume of ice was determined using a different methodology. Using space-borne remote sensing optical data Zhang et al. (2017) were able to determine the extent of the ice cover that breakups and accumulates to cause ice jams in the Slave River Delta in the Northwest Territories of Canada. Empirical relationships with air temperature allowed the thickening and ablation of the ice cover to be estimated and, along with the width of the ice cover, the ice volumes could be determined. A comparison of the distributions is provided in Figure 13.

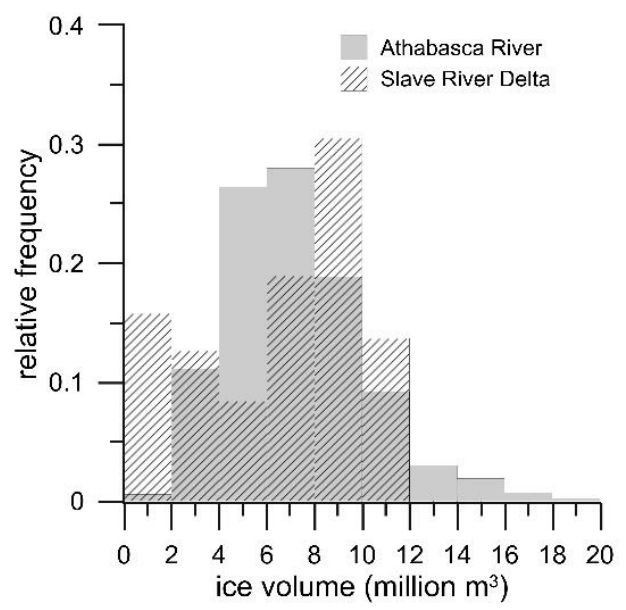

Figure 13. Histograms of the volumes of ice forming ice accumulations and jams along the Athabasca River at Fort McMurray (Alberta) and the Slave River Delta (Northwest Territories).

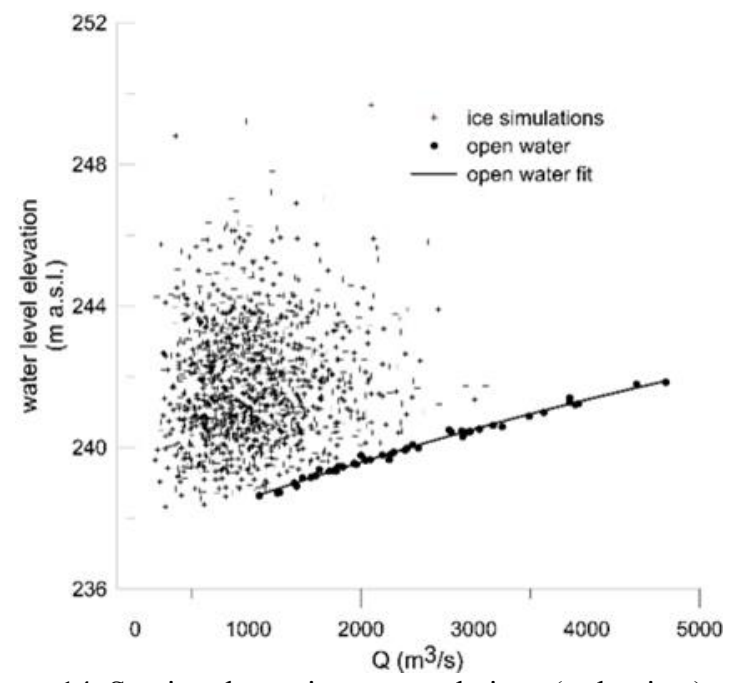

Figure 14. Staging due to ice accumulations (red points) compared to maximum annual open water staging (blue dots and line). 


\subsection{Calculating the Probable Maximum Ice-Jam Staging}

The ice accumulation and jamming simulations from the MOCA framework were plotted with total discharge vs. backwater staging at the Athabasca gauge in Figure 14. The figure emphasizes the chaotic behavior of ice flooding on backwater level elevations. It is interesting to note that the maximum water level attained from all simulations, approximately $250.43 \mathrm{~m}$ a.s.l., which is deemed the $P M F_{\text {ice }}$ in this case, occurs at a relatively low flow.

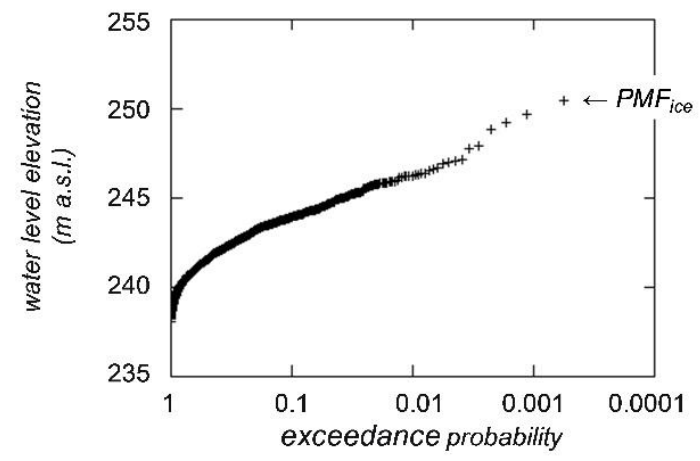

Figure 15. Weibull distribution of all backwater level elevations simulated at the Athabasca gauge.

All maximum backwater staging was also plotted as a Weibull distribution in Figure 15. The maximum water level elevation $P M F_{\text {ice }}$ of approximately $250.43 \mathrm{~m}$ a.s.1. is deemed to be the highest staging possible through ice jamming. The distribution was constructed from results from approximately 1,776 model runs; further model runs may reveal a somewhat higher $P M F_{\text {ice }}$ staging.

$P M F$ is widely used as a design criterion for new dams and other hydraulic structures as well as a security assessment for existing dams and impounding structures to avoid devastating floods and dam failures ( $\mathrm{Li}$ et al., 2010). It currently serves as the design standard for many dams in United States (Graham, 2000). However, in cold regions, floods induced by ice jams are a significant challenge in which river ice processes also play a key role. The complex hydro-meteorological and structural processes that lead to ice jam formation, progression, and release are highly site specific (Beltaos, 2011). Furthermore, historical data are not always available especially the peak iceinfluenced stages. Where peak discharges for ungauged locations may be estimated from nearby upstream or downstream gauges, ice-induced stages cannot be meaningfully transposed from other locations (Lindenschmidt et al., 2018). Nevertheless, several direct and indirect methods have been proposed in the literature to estimate ice-affected stages and maximum possible stages (White and Beltaos, 2008). When ice jam stages are available, graphical methods with Weibull plotting positions can be used. For instance, Beltaos (2011) estimated the maximum possible stage for the Peace River at Peace Point based on local morphology and historical data. In some cases, historical ice jam stages may also be gathered from a mixture of sources with varying reliability (Gerard and Karpuk, 1979).

When historical data are not available, synthetic methods are used (Beltaos, 2010). The synthetic method is an indirect approach to develop a stage-frequency relationship based on empirical observations or statistical and mathematical analyses (White and Beltaos, 2008). If the amount of data is inadequate, peak annual ice-affected conditions such as discharge, ice thickness and jam locations, are fed into the hydraulic models to estimate maximum ice-affected stages (Tuthill et al., 2003). Noting that empirical evidence does not support the assumption of discrete stage outcomes, Beltaos (2012) proposed a new synthetic method called the distributed-function method in which peak stage can take on any value between discharge-dependent upper and lower envelopes. However, all proposed indirect methods suffer from errors associated with extrapolation at the upper end (White and Beltaos, 2008).

Computational estimates can easily exceed bankfull conditions but in reality, water and ice will escape from the main channel and spread out onto the floodplain. This imposes a practical limit on the maximum probable ice-affected stage regardless of the magnitude of the flow (White and Beltaos, 2008). When a certain flow threshold is exceeded, ice jams become unstable and release reverting to open-water conditions (Beltaos, 2008). In the Athabasca River along the Fort McMurray, the flood water level is $246.8 \mathrm{~m}$ a.s.l. Above this level, the low-lying areas along the left bank of the Clearwater River gets flooded (Sun and Trevor, 2018). Thus, the estimation of $P M F_{\text {ice }}$ to be approximately $250.43 \mathrm{~m}$ a.s.l. is reasonable.

This threshold, $P M F_{\text {ice }}$ can serve as an important benchmark, not only for design purposes for areas prone to ice jamming but also for floodplain delineations. Our method provides an advantage over existing methods as it is stochastic in nature and the maximum probable stage is generated from hundreds of possible ice-jamming simulations. Where open water discharges and water levels can be associated with a smooth deterministic curve, backwater levels from ice accumulations or the more severe ice jam events require stochastic approaches (Lindenschmidt, 2016).

The major usefulness of $P M F_{\text {ice }}$ will be its application in the design purposes of hydraulic infrastructures in cold regions where previous experiences have shown that designs based on 100-year floods or open-water $P M F$ are not adequate for flood protection. For instance, the town of the Peace River in western Canada relies on a dike system for protection against floods. After an extreme flood event (with peak flow of 15,600 m³ in 1972 , the dike was raised in 1974 to protect against a design flow of $17,839 \mathrm{~m}^{3} / \mathrm{s}$. In 1981, the dike crests were further raised by $1 \sim 1.2 \mathrm{~m}$ after the annual exceedance probability of 1:100year open water flood was calculated to be $20,133 \mathrm{~m}^{3} / \mathrm{s}$. However, a major open-water flood occurred in 1990. In 1992, when ice-jam flooding again overtopped the town's dikes, an additional $0.5 \mathrm{~m}$ of freeboard was added to the existing dikes based on the revised design discharge of $21,200 \mathrm{~m}^{3} / \mathrm{s}$. But the dikes were again overtopped and bypassed at several locations in the town when an ice-jam flood event occurred in 1997 near the Heart River Bridge. As a result, an additional flood wall was 
built and the height of bridge was raised in 1999 (Bekevich, 1990). This was the last of the structural flood control measures implemented. Lindenschmidt et al. (2016) note that even current dike crest elevations are not designed based on ice-jam flood events that can result in significantly higher water levels than open water floods. Thus, $P M F_{\text {ice }}$ offers a proactive design approach to minimize flood risk and reduce damage related costs. Furthermore, designing the structures based on $P M F_{\text {ice }}$ also avoids the problem of extrapolating short-term records (Lawford et al., 1995).

\section{Conclusions}

An approach is presented to determine the maximum possible backwater staging that would occur at a location along a river due to ice jamming, coined here as the probable maximum ice-jam flood $P M F_{\text {ice. }}$ To the authors' knowledge, this is the first published attempt to quantify such a flood level. The icejam flood risk prone area along the Athabasca River at Fort McMurray was chosen as a test site, but the method is easily transferable to other cold-regions rivers. The method requires the calibration of frequency distributions of two boundary conditions, downstream water level elevation and inflowing volume of ice constituting the ice jams, to be calibrated by comparing simulated stage frequency distributions at the end of breakup and during ice-jam events with those constructed from observed stage levels. The distributions obtained for the volume of jam ice compare well with ice volumes obtained in other studies. We believe, this method of calculating $P M F_{\text {ice }}$ will be extremely useful for planners and engineers who wish to follow a more "proactive" design procedure of flood mitigation infrastructure, in which an upper threshold can better guide design requirements instead of a "reactive" design procedure in which infrastructure are remedied to only exceed flood levels and extents from the previous flood events.

Acknowledgments. Funding for this research was provided by the University of Saskatchewan. The authors are grateful for constructive comments from the reviewers to improve the manuscript.

\section{References}

Aaltonen, J. and Huokuna, M. (2017). Flood mapping of river ice breakup jams in River Kyrönjoki delta. CGU HS Committee on River Ice Processes and the Environment 19th Workshop on the Hydraulics of Ice Covered Rivers. Whitehorse, Yukon, Canada, 912 July 2017. http://cripe.ca/docs/proceedings/19/Aaltonen-Huokuna-2017.pdf

Bekevich Engineering Ltd. (1990). Peace River Dykes Project. Report prepared by Bekevich Engineering Ltd.

Beltaos, S. (2008). Onset of breakup. River Ice Breakup, ed. Beltaos, Spyros, 167206.

Beltaos, S. (2010). Assessing ice-jam flood risk: Methodology and limitations. 20th IAHR International Symposium on Ice.

Beltaos, S. (2011). Alternative method for synthetic frequency analysis of breakup jam floods. CGU HS Committee on River Ice Processes and Environment, pp. 18-22.

Beltaos, S. (2012). Distributed function analysis of ice jam flood frequency. Cold Reg. Sci. Technol., 71, 1-10. https://doi.org/10.1016/j. coldregions.2011.10.011

ECCC. (2013). RIVICE - User's Manual. Environ. Clim. Change Can., http://giws.usask.ca/rivice/Manual/RIVICE_Manual_2013-01-11. pdf

Felder, G., Zischg, A., and Weingartner, R. (2017). The effect of coupling hydrologic and hydrodynamic models on probable maximum flood estimation. J. Hydrol., 550, 157-165. https://d oi.org/10.1016/j. jhydrol.2017.04.052

Gerard, R. and Karpuk, E.W. (1979). Probability analysis of historical flood data. J. Hydraul. Div., 105(9), 1153-1165.

Graham, W.J. (2000). Should dams be modified for the probable maximum flood? J. Am. Water Resour. Assoc., 36(5), 953-963. https://doi org/10.1111/j.1752-1688.2000.tb05701.x

Hosseini, N., Chun, K.P., Wheater, H., and Lindenschmidt, K. E. (2017). Parameter sensitivity of a surface water quality model of the lower South Saskatchewan River - Comparison between ice-on and ice-off periods. Environ. Model. \& Assess., 22(4), 291-307. https:// doi.org/10.1007/s10666-016-9541-3

Lawford, R., Prowse, T., Hogg, W., Warkentin, A., and Pilon, P. (1995). Hydrometeorological aspects of flood hazards in Canada. Atmosphere-Ocean, 33(2), 303-328. https://doi.org/1 0.1080/07055900.19 95.9649535

Li, S., Cain, S., Wosnik, M., Miller, C., Kocahan, H., and Wyckoff, R. (2010). Numerical modeling of probable maximum flood flowing through a system of spillways. J. Hydraul. Eng., 137(1), 66-74. https: //doi.org/10.1061/(ASCE)HY.1943-7900.0000279

Lindenschmidt, K.E., Huokuna, M., Burrell, B.C., and Beltaos, S. (2018). Lessons learned from past ice-jam floods concerning the challenges of flood mapping. Int. J. River Basin Manage., (online), 113. https://doi.org/10.1080/15715124.2018.1439496

Lindenschmidt, K.E., Das, A., Rokaya, P., and Chu, T. (2016). Ice jam flood risk assessment and mapping. Hydrol. Process., 30, 3754 3769. https://doi.org/10.1002/hyp.10853

Lindenschmidt, K.E. (2017a). RIVICE - a non-proprietary, opensource, one-dimensional river-ice and water-quality model. Water, 9 , 314. https://doi.org/10.3390/w9050314

Lindenschmidt, K.E. (2017b). Using stage frequency distributions as objective functions for model calibration and global sensitivity analyses. Environ. Model. Software, 92, 169-175. https://doi.org/10.10 16/j.envsoft.2017.02.027

Lindenschmidt, K.E., Sydor, M., Carson, R.W., and Harrison, R. (2012). Ice jam modelling of the Lower Red River. J. Water Resour. Prot., 4(1), 1-11. https://doi.org/10.4236/jwarp.2012.41001

Lindenschmidt, K.E., Pavey, J.F., Michalek, D., Drastig, K., Petrow, T., and Vorogushyn, S. (2008). Modelling dyke breaches and probable ma-ximum flood in river catchments to reduce uncertainty in flood fre-quency analyses. 10th National Hydrology Symposium, British Hy-drological Society, Exeter, pp. 15-18. http://www.hydrology.org. uk/dms-files.php?id=86 3 \&action $=$ doc

Sun, W. and Trevor, B. (2018). Multiple model combination methods for annual maximum water level prediction during river ice breakup. Hydrol. Process., 32(3), 421-435. https://d oi.org/10.1002/hyp.114 29

Tuthill, A.M., Wuebben, J.L., Daly, S.F., and White, K.D. (1996). Probability distributions for peak stage on rivers affected by ice jams. J. Cold Regions Eng., 10(1), 36-57. https://doi.org/10.1061/(ASCE) 0887-381X(1996)10:1(36)

Tuthill, A., Vuyovich, C., and White, K. (2003). Ice-affected stage-frequency development along the Connecticut River. Proceeding of, 12th Workshop on the Hydraulics of Ice Covered Rivers.

Vorogushyn, S., Merz, B., Lindenschmidt, K.E., and Apel, H. (2010). A new methodology for flood hazard assessment under consideration of dike breaches. Water Resour. Res., 46, W08541. https://doi. org/10.1029/2009WR008475 
White, K.D. (1999). Forecasting systematic ice jam occurrence along the Yukon River, Alaska. 10th CRIPE Workshop on the Hydraulics of Ice Covered Rivers. pp. 31-43. http://cripe.civil.ualberta.ca/Downloads/10th Workshop/White 1999.pdf

White, K. and Beltaos, S. (2008). Chapter 9: development of ice-affected stage frequency curves (Vol. 3), Water Resources Publications, Highlands Ranch, Co., USA.ECCC (20013) RIVICE Model - User's Manual. Environment and Climate Change Canada. http://giws.usa-
sk.ca/rivice/Manual/RIVICE Manual 2013-01-11.pdf

WMO. (2009). Manual on Estimation of Probable Maximum Precipitation (PMP). World Meteorological Organization report no. 1045. ISBN 978-92-63-11045-9. http://www.wmo.int/pages/prog/hwrp/publications/PMP/WMO\%201045\%20en.pdf

Zhang, F., Mosaffa, M., Chu, T., and Lindenschmidt, K.E. (2017). Using remote sensing to parameterize ice jam modeling for a northern inland delta. Water, 9, 306. https://doi.org/10.3390/w9050306 